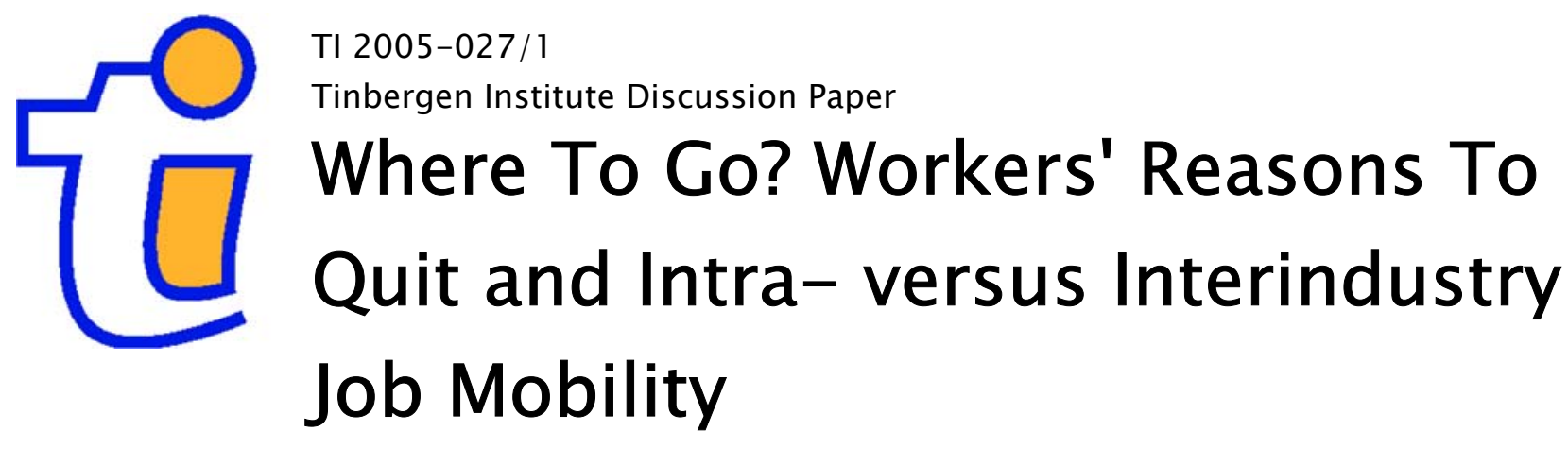

Josse Delfgaauw

Department of Economics, Erasmus Universiteit Rotterdam, and Tinbergen Institute. 


\section{Tinbergen Institute}

The Tinbergen Institute is the institute for economic research of the Erasmus Universiteit Rotterdam, Universiteit van Amsterdam, and Vrije Universiteit Amsterdam.

Tinbergen Institute Amsterdam

Roetersstraat 31

1018 WB Amsterdam

The Netherlands

Tel.: $\quad+31(0) 205513500$

Fax: $\quad+31(0) 205513555$

Tinbergen Institute Rotterdam

Burg. Oudlaan 50

3062 PA Rotterdam

The Netherlands

Tel.: $\quad+31(0) 104088900$

Fax: $\quad+31(0) 104089031$

Please send questions and/or remarks of nonscientific nature to driessen@tinbergen.nl.

Most TI discussion papers can be downloaded at http://www.tinbergen.nl. 


\title{
Where To Go? \\ Workers' Reasons to Quit and Intra- versus \\ Interindustry Job Mobility
}

\author{
Josse Delfgaauw \\ Tinbergen Institute, Erasmus University Rotterdam*
}

July 2005

\begin{abstract}
We show that workers' reasons for quitting their job affect their decision to stay in or leave their industry, using survey data among public sector employees in the Netherlands. Workers quitting for e.g. pay, work pressure, or job duties move relatively often to another industry, in contrast to workers quitting for commuting time or the atmosphere at work. This suggests that workers use their experience in the initial job to update their expectations on other jobs in the industry, as the first set of job aspects is more likely to be related among jobs within an industry than the latter. Further, it is shown that workers' reasons to quit fully explain the differences in wage growth between intra- and interindustry job movers. Lastly, we find that workers who quit for pay or management often leave the public sector altogether.
\end{abstract}

Keywords: Reasons to quit, Job mobility, Wages, Public sector workers.

JEL-codes: J28, J31, J33, J45, J63.

*Address: Tinbergen Institute, Erasmus University, P.O.Box 1738, 3000 DR, Rotterdam, The Netherlands. E-mail: delfgaauw@few.eur.nl. 


\section{Introduction}

In many countries, the public sector faces problems recruiting and retaining skilled personnel (OECD, 2001). Borjas (2003) shows that since 1970, the private sector in the US has become financially more attractive to high-skilled workers, as wage dispersion has increased more in the private sector than in the public sector. The Audit Commission (2002) reports that the main reasons for workers to leave the public sector in the UK are bureaucracy, workload, pay, and management. Workers felt that these problems were specific to the public sector. Still, many workers remained in the public sector, as "personal fulfilment made up for the lack of financial rewards" (p. 29). Clearly, nonpecuniary factors influence workers' decision to stay in or leave the public sector. Moreover, it suggests that workers use their on-the-job experience to evaluate other jobs in their sector.

Neal (1999) draws a similar conclusion. He examines labour mobility in the US and distinguishes between 'simple' and 'complex' job change. Complex job mobility involves a change in career, empirically defined as a change in both industry and occupation. Neal develops a model in which workers first search for a suitable career and subsequently search for a suitable employer. Evidence from the National Longitudinal Survey of Youth supports the model. Complex job changes are less common among experienced workers than among unexperienced workers, and the likelihood of a complex job change falls sharply after a worker has changed employer without changing career. Based on this evidence, Neal concludes that "many workers are apparently using on-the-job experience as a means of gaining information about possible careers" (p. 239).

This paper shows that workers' self-proclaimed reasons for quitting their job affect their decision to stay in their current industry or to move to another industry. We employ data from a survey among employees who either accepted or left a public sector job in the Netherlands in 2001. Employees who quit their previous job had to indicate the importance of 19 different job aspects in their decision to leave the job. We find that the motives for job change of workers who stay in their industry differ from the motives of workers who change industry, in a fairly intuitive pattern. 
Workers are more likely to move to another industry when pay, work pressure, working conditions, job duties, or management are important in the decision to quit. In contrast, dissatisfaction with the opportunities for training, the atmosphere at work, the number of hours worked, or commuting time makes it more likely that a worker stays in the current industry. We argue that correlation of job aspects among jobs within an industry may explain most of these findings, as the first group of job aspects is more likely to have an industry-specific component than the latter. Moreover, we show that the different motives for job change lead to differences in wage growth: the apparent wage premium of interindustry job movers is fully explained by workers' reasons for quitting.

Although the diversity of jobs within an industry is large, the jobs open to a specific worker may share some features. The salary spread may be limited, especially when firms offer 'competitive' salaries or when salary negotiations take place at industry-level. Similarly, the jobs open to a specific worker may have tasks in common, and working conditions may depend partially on the specific industry. Conversely, other job aspects are determined solely by the combination of a worker and an organisation. For instance, commuting time and the atmosphere at work are unlikely to be influenced by the industry.

When jobs within an industry have features in common, experience in one job generates information on other jobs, but only on those job aspects that have an industry-specific component. If one of these job aspects causes a worker to quit, this worker may need to change industry in order to find a better suited job. Conversely, dissatisfaction with a job aspect for which jobs within the industry differ sufficiently does not necessitate a change in industry. A move to another hospital is of little use to a nurse who dislikes her job duties, but may solve the problems of a nurse who dislikes her colleagues. Similarly, a teacher may shorten commuting time by moving to another school, but it is unlikely that he improves his salary substantially. Our findings thus suggest that — in line with Neal (1999) - workers use their on-the-job experience to update their expectations of other jobs in the industry.

It is interesting to note that respondents considered financial matters less important in their decision to quit than job duties, atmosphere at 
work, and management. This paper is not the first to document that nonpecuniary factors are important determinants of quit behaviour. For instance, Akerlof et al. (1988) find that more people quit for nonpecuniary reasons than for pecuniary reasons, and argue that "any realistic portrait of labor turnover must include a role for nonpecuniary rewards" (p. 498). Nonetheless, many authors have ignored these factors in studies of labour mobility, possibly due to lack of data. ${ }^{1}$

Further, we look into the main reasons for workers to leave the public sector altogether. We find that public sector workers who quit for pay or management take up employment in the private sector relatively often. In contrast, when the possibilities for training are important in the decision to quit, workers are more likely to stay in the public sector. These findings are an indication of the relative strengths and weaknesses of public sector jobs.

The remainder of this paper is organized as follows. The next section shortly discusses the literature on the causes and consequences of job mobility. Section 3 describes the data. In Section 4, we report the effects of workers' reasons for quitting on their wage growth and relate these findings to earlier work on the relation between wages and workers' evaluation of different job aspects. This provides us with an indication of how our data compares to the data used in other studies. Section 5 discusses the effects of workers' reasons for quitting on the decision to stay in or leave the industry of employment. Furthermore, this section looks into workers' reasons to leave the public sector altogether. Section 6 concludes.

\section{Job mobility}

A large literature has evolved on the causes and consequences of job mobility. Bartel (1982) studies the effects of several job attributes on quit behaviour, and finds that for young men, repetitive work and bad working conditions increase the probability that a worker quits, whereas for older men repetitive work may actually decrease this probability. Higher starting wages decrease the likelihood of a separation (Topel and Ward, 1992),

\footnotetext{
${ }^{1}$ See, among many others, Topel and Ward (1992), Light and McGarry (1998), Campbell (2001), McCaughlin and Bils (2001), and Lima (2004).
} 
whereas workers are more likely to quit jobs that are complex (Weiss, 1984), or that pose health and safety risks (Viscusi, 1979). Altonji and Paxson (1992) show that females whose family composition has changed obtain larger changes in the number of hours worked when they move to another employer than by staying in the same job. The authors argue that adjusting working hours to changing preferences may be easier by changing jobs than within a job.

Workers' own assessment of their job also provides information on the likelihood of a quit. Freeman (1978) already found that job satisfaction is negatively related to the probability that a worker quits, see also Akerlof et al. (1988) and Clark et al. (1998). A decomposition of job satisfaction into satisfaction with different job aspects reveals that satisfaction with job security is the best predictor of quits among UK workers (Clark, 2001), whereas satisfaction with the type of work appears most important in Denmark (Kristensen and Westergard-Nielsen, 2004).

Concerning the consequences of a quit, Topel and Ward (1992) find that one-third of the total wage growth of young men in their first ten years in the labour market occurs through job changes. Akerlof et al. (1988) show that workers who quit out of dissatisfaction with pay usually obtain a wage increase, whereas a substantial fraction of workers who quit for nonpecuniary reasons take a wage cut. Still, both groups report being better off after the job change. Keith and McWilliams (1997) find that the wage growth of employees who quit for family-related reasons is smaller than the wage growth of both non-movers and workers who quit for non-family-related reasons. Relatedly, a common finding in the literature is that job movers who voluntarily left their job fare better financially than workers who are laid off or discharged (McLaughlin, 1991, Keith and McWilliams, 1997). ${ }^{2}$

A common feature of these studies is that the data used contains both movers and non-movers. As we only have information on workers who entered or left a public sector job, we cannot compare movers to nonmovers. The contribution of this paper lies in the extensive set of reasons for quitting, which we can relate to a worker's decision to stay in or leave the current industry and to the change in a worker's wage.

\footnotetext{
${ }^{2}$ The literature on displaced workers is surveyed by Kletzer (1998) and Kuhn (2002).
} 


\section{The data}

In 2002, the Dutch Ministry of the Interior and Kingdom Relations conducted a survey among employees who started in or left a public sector job in 2001. Information about employees who had either entered or left an organisation in the public sector was collected from salary administrations. Representative samples were drawn and 22,000 employees who left an organisation and 20,250 employees who entered an organisation received a questionnaire, yielding 7,854 and 6,942 respondents, respectively. ${ }^{3}$ The data are weighted in two steps. First, weights are applied so as to reflect the information from the salary administrations on gender, age, tenure, province, and wage for each industry in the public sector independently. These industries are the central government, local governments, education, research, the police, the judicial system, defense, and university hospitals. ${ }^{4}$ Second, each industry receives a weight corresponding to its share in total public sector employment.

We merge the two samples, and divide the respondents in four groups, depending on their former and new industry of employment. Stayers move to another employer within the same industry, movers leave their former industry of employment but remain employed in the public sector, leavers move from the public sector to the private sector, and entrants move from the private sector to the public sector. This gives 3,105 stayers, 1,967 movers, 2,483 entrants, and 1,103 leavers. ${ }^{5}$ Partial non-response reduces these numbers to $2,261,1,430,1,912$, and 717 , respectively. We have removed another 64 stayers, 34 movers, 79 entrants, and 28 leavers because they reported implausible wage levels or wage changes. ${ }^{6}$

\footnotetext{
${ }^{3}$ Employees who moved from one job in the public sector to another may have received two questionnaires. However, there is no evidence of duplicate cases in the dataset.

${ }^{4}$ The data also distinguish nine different industries in the private sector.

${ }^{5}$ The focus on job-to-job mobility removes 2,904 respondents from the sample who did not have a job before entering their public sector job, as well as 3,234 respondents who did not take up another job after leaving their public sector job.

${ }^{6}$ We have set the floor and the ceiling for both the former and the new hourly wage at 3 euro and 60 euro, respectively. The floor is slightly below the legal minimum wage for 18-year old employees, and the ceiling is (in terms of monthly income) slightly above a Minister's wage in the Netherlands. The cut-off levels for relative wage change have (arbitrarily) been set such that workers whose hourly wages more than halved or more than tripled were excluded. Inspection of the data reveals that most of these cases
} 
One of the main purposes of the survey was to gain insight into employees' reasons for entering or leaving a public sector job. The respondents who had left a job were asked to indicate on a 5-point scale the importance of 19 job aspects in their decision to leave their old job. Furthermore, they had to rank the three most important reasons for quitting. We construct 'reason-to-quit' variables in the following way, as proposed by Mathios (1989). A reason-to-quit variable is assigned the value 0 if the respondent did not consider this job aspect important in the decision to quit (1-3 on the 5-point scale), the value 1 if the respondent considered the job aspect important (4-5 on the 5-point scale), but did not indicate it as one of the three most important reasons for quitting, the value 2 if this job aspect was the third most important reason, the value 3 if this job aspect was the second most important reason, and the value 4 if it was the most important reason for quitting. ${ }^{7}$

Table 1 lists for each group of job movers the means of the reason-toquit variables. Interestingly, financial motives appear less important than dissatisfaction with management, (future) job duties, or the atmosphere at work. ${ }^{8}$ Several differences between the four groups emerge from Table 1. Relatively few stayers indicate that they were unhappy with their job duties, whereas commuting time is mentioned more frequently by stayers than by the other groups. Leavers complain relatively little about commuting time and work pressure, but complain most about their former management and pay. Movers voice dissatisfaction about (future)

involve typo's, misspecifications, or misinterpretation of the questions (for instance, some respondents appear to report yearly rather than monthly income).

${ }^{7}$ This specification imposes arbitrary weights on the questions regarding the importance of job aspects, which is also acknowledged by Mathios (1989). We have checked the robustness of our results by using different specifications. Specifications including only the most important reason for quitting or the three most important reasons for quitting (equally weighted) yield qualitatively similar results, but perform worse than the 0-1-2-3-4 specification in terms of explanatory power. Furthermore, we used a specification which imposes no structure of weights, by inserting a dummy variable for each level of importance of all job aspects. Again, qualitatively similar results emerge, although for several job aspects, the magnitude of the coefficients is not monotonically increasing in the level of importance. Still, the estimated effects of job aspects being 'most important' relative to being 'not important' closely resemble the estimations reported in the paper.

${ }^{8}$ Note that this need not imply that employees care little about the level of their wage. Due to the rather compressed wage structure in the Netherlands, employees may rationally expect a job change to yield little financial gain. 
job duties relatively strongly, whereas entrants often emphasize (the lack of) possibilities for training and the number of hours worked. The threat of involuntary separations also prevails more often among entrants than among the other groups. ${ }^{9}$

Summary statistics for several worker and job characteristics are listed in Table 2. The variables married and children at home are dummy variables, representing whether or not the respondent has a partner or children, respectively. The education dummies depend on the highest completed level of schooling. Low education comprises respondents who completed primary school only and respondents who completed lower vocational education. Medium education consists of workers with high school education or medium vocational education, and higher vocational education and university speak for themselves. Tenure describes the number of years a worker has been employed by his former employer. Experience is measured as the number of years since the respondent finished education. Hourly wages are computed from the respondents' monthly income and contractual hours.

In line with Neal (1999), stayers are on average more experienced than the other groups. Furthermore, the fraction of stayers with higher vocational education is relatively large. Entrants have less education, experience, and tenure, and earn less than the other groups. Leavers obtain the largest wage growth, whereas stayers receive the smallest increase in hourly wage. The average increase in hourly wage is 9.15 percent, which is close to the estimates by Topel and Ward (1992).

This study focusses on job-to-job mobility. We also have data on the reasons to quit of 237 employees who left a public sector job but did not take up another job. In comparison to the figures in Table 1 and Table 2,

\footnotetext{
${ }^{9}$ Unfortunately, the survey among employees who entered a public sector job did not explicitly ask whether the respondent quit their previous job. Hence, there may be some actual layoffs and discharges in the sample. The survey among employees who left a public sector job did ask whether the employee voluntarily left the job or had been displaced. Given the evidence in the literature that the consequences of a separation differ between workers who quit and workers who are displaced, we have checked whether elimination of all respondents who considered threats of involuntary separations important in their decision to quit would affect our results. It turns out that all results are qualitatively similar in this restricted sample, except for the effect of the reason-to-quit variable 'contractual hours' on wage growth, which becomes smaller and insignificant (see Table 3 ).
} 
these employees were more often female, less educated and worked fewer hours. They considered work pressure and in particular the combination of work and private life more important in their decision to quit. By contrast, financial prospects and future job duties were less important. This points to the argument that some women may invest less in human capital, because they expect to withdraw (temporarily) from the labour market at some point in time to dedicate themselves to their family (see Weiss and Gronau, 1981, Blau and Ferber, 1986, and Polachek and Kim, 1994).

\section{Workers' reasons to quit and wage growth}

Workers change jobs to improve upon job aspects causing discomfort. Hence, it is likely that the new job offers better conditions with respect to these troubling job aspects. Unfortunately, we can not assess the effect of the reasons to quit on all job aspects, as the survey did not ask workers to compare job aspects of their former and new job. The data do allow us to estimate the effect of workers' reasons for quitting on their wage growth. Hence, we estimate:

$$
\Delta\left(w_{i}\right)=\alpha+\beta Q_{i}+\gamma X_{i}+e_{i}
$$

where $\Delta\left(w_{i}\right)$ is the difference in log hourly wage between the new and the former job of employee $i$ and $Q_{i}$ is a vector of the 19 reason-to-quit variables. $X_{i}$ is a vector of other explanatory variables, containing the change in the number of hours worked, tenure, tenure-squared, experience, experience-squared, and dummies for gender, minority, partner, children, educational levels, and former and new industry. ${ }^{10}$

The results of the estimation of equation (1) reported in Table 3 square well with the findings of previous studies. In line with Keith and McWilliams (1997), but in contrast to Loprest (1992), we find no evidence of a smaller wage effect of a job change for females. On the contrary, after the inclusion of the reasons-to-quit variables, the coefficient on the

\footnotetext{
${ }^{10}$ Elimination of constant characteristics from the set of explanatory variables turns out not to affect the results.
} 
female dummy turns positive. Wage growth is positively related to the level of education, as in Connolly and Gottschalk (2000), Lima (2004), and Villanueva (2004), using data on US, Portuguese, and German workers, respectively. Employees with a partner obtain a significantly smaller wage increase than singles. Villanueva (2004) reports a marriage effect of similar magnitude.

The reason-to-quit variables are jointly significant at the 0.01 level, and several are individually significant as well. We find that the threat of an employer-initiated separation leads to significantly smaller wage growth. This is in line with evidence that job changers who quit obtain larger wage increases than job changers who are laid-off or discharged (McLaughlin, 1991, Keith and McWilliams, 1997). However, we can not rule out that this result is caused by a (small) number of actual layoffs and discharges in the sample. This suspicion is reinforced by the finding that the effect becomes insignificant if we restrict the sample to the survey among employees who left a public sector job (recall that this survey explicitly asked workers whether they quit their job or were displaced).

In line with Akerlof et al (1988), we find that employees leaving their job out of dissatisfaction with pecuniary rewards obtain relatively high wage growth. The specification of the reason-to-quit variables implies that an employee for whom rewards was the most important reason to quit obtains a wage increase which is 10.8 percentage points higher than an employee for whom rewards were not important in the decision to quit.

Responsibility and autonomy are also being rewarded, as employees complaining about this job aspect receive significantly larger wage increases. Predictions of both theory and previous empirical work are mixed. Efficiency wage theory predicts a positive relation between employees' autonomy and wages, while the theory of compensating differentials suggests that employees may be willing to give up a fraction of their income in return for more autonomy (see e.g. Dur and Glazer, 2004). In line with our result, some authors find a negative relation between supervision and pay (Krueger, 1991, Kruse, 1992, Rebitzer, 1995), while some find a positive relation (Smith et al. 1997), and others find no relation (Leonard, 1987, Brunello, 1995). Similarly, Brown and Sessions (2002) report a positive relation between supervisors' pay and the number of supervisees, but 
Frey and Kucher (1999) find no effect of the number of subordinates on supervisors' wages.

Somewhat surprising is the positive relation between a quit for the number of hours worked and the wage change. Inspection of the data reveals that workers for whom the number of hours worked was important in their decision to quit on average increase the number of hours worked, but variation is large.

Lastly, dissatisfaction with work pressure or with the combination of work and private life appears to induce workers to accept significantly smaller wage growth. The specification of the reason-to-quit variables implies that the difference between the wage growth of an employee for whom work pressure was the most important reason for quitting and an employee who had no problem with work pressure is 4.8 percentage points, about half of the average wage increase in the sample. This is close to estimates by Villanueva (2004), using data from the German Socio-Economic Panel. He finds that job movers who indicate that their work load has worsened obtain 5 percent higher wage growth, whereas an improvement of work load yields 3 percent smaller wage growth, both relative to workers without a change in work load.

Overall, the findings presented in this section fit reasonably well into the previous literature on the relation between wages and workers' evaluation of different job aspects. This bolsters our confidence that the findings in the next section extend beyond the population under study here. The next section shows that workers' evaluation of job aspects not only affects their wage, but also their decision on where to (seek) work.

\section{$5 \quad$ Where to go?}

\subsection{Intra- vs interindustry mobility}

The theory of job shopping postulates that workers are uncertain about their valuation of jobs (Johnson, 1978, Jovanovic, 1979). By spending time on a job, workers learn their true valuation of the job. As such, a job is an experience good. A separation occurs when it becomes clear that the match between the worker's preferences or productivity and the 
conditions of the job is bad. At this point, the worker is still clueless about his valuation of other jobs, and, hence, randomly applies for a new position. This theory explains several empirical findings, including the positive relation between tenure and wages in cross-sectional data and the relatively high turnover frequency of workers early in their career.

Yet, it is hard to imagine that working in one job provides no information on at least some aspects of other jobs in the economy. The information a worker obtains in the current job extends in particular to similar jobs within the industry. University professors know that the job duties of a position at another university will include a mix of teaching, research, and management tasks, despite lacking the experience of working at this university. In general, when the jobs within an industry open to a specific worker have one or more job characteristics in common, working in one job yields information on the other jobs. Then, workers' expectations of other jobs in the industry are affected by their valuation of certain job aspects in their current job. This implies that a bad experience with a job aspect correlated among jobs within the industry makes a change in industry more likely. Hence, workers' experience in a job not only influences the decision to stay in or leave the job, but also the decision to stay in or leave the industry.

A priori, it is unfeasible to create an indisputable division of the 19 job aspects listed as potential reasons for quitting into correlated and independent features of jobs within an industry. Yet, it can be argued that some job aspects are more influenced by the industry than others. For instance, atmosphere at work and commuting time are largely determined by the organisation and the worker, and are unlikely to be related among jobs within an industry. Other job aspects, such as job duties, rewards, and working conditions, are more likely to be related among the subset of jobs within an industry open to a single worker. Intuitively, working in one hospital provides a decent indication of job duties and salary at other hospitals, but may be less informative about the atmosphere at another hospital. Hence, we would expect that workers quitting for atmosphere at work or commuting time are more likely to stay in the industry than workers who quit for job duties, rewards, or working conditions.

The information on workers' reasons to quit provides us with the op- 
portunity to test this prediction. Thereto, we explore the differences in the reasons to quit of stayers, movers and leavers. These employees all quit jobs in public sector industries, but only stayers have taken a new job in the same industry. ${ }^{11}$ Table 4 shows the results of a logistic regression of the reasons to quit on the decision to stay in or leave the industry of employment. The dependent variable is 0 if the respondent is a stayer, and 1 if the respondent is a mover or a leaver. Hence, a positive coefficient implies a positive relation between the variable and the probability that a respondent leaves the industry, whereas a negative coefficient implies that a higher value of the variable increases the probability that a respondent stays in the industry.

From Table 4, we conclude that workers' reasons to quit indeed affect their decision to stay in or leave the industry. The arising pattern supports the argument that workers update their expectations of specific aspects of other jobs in the industry. Workers who quit for pay, work pressure, working conditions, or job duties are more likely to move to another industry. These job aspects are likely to be partially determined by the industry, as it seems unlikely that moving to a similar job yields substantially higher pay, radically different job duties, or more favourable working conditions. Therefore, moving to another job within the industry may not suffice to improve the valuation of these job aspects. By contrast, a quit for training opportunities, atmosphere at work, the number of hours worked, or commuting time decreases the probability that the worker moves to another industry. Arguably, these job aspects are primarily determined by the organisation and the worker, and are little influenced by the industry. Somewhat puzzling are the positive coefficients on management and leadership. Perhaps management style varies less within an industry than across industries.

Overall, the findings in Table 4 suggest an extension of the theory of job shopping. By forming a match, workers not only obtain information on their own job, but also on certain aspects of other jobs in the industry. Hence, workers' experience on the job not only aides them in deciding whether to stay in or leave the job, but also in deciding where to go.

\footnotetext{
${ }^{11}$ The lack of data on employees who change jobs within the private sector hinders a similar estimation for industries in the private sector.
} 


\subsection{Workers' reasons to leave the public sector}

The information on the reasons for quitting can also be used to determine which job aspects drive workers out of the public sector. Thereby, we get an indication of the job aspects that need attention if retention rates are to be improved. By regrouping the respondents, we can use the same method as in the previous subsection. Stayers and movers have changed jobs within the public sector, whereas leavers have moved from a public sector job to a job in the private sector. Table 5 reports the result of a logistic regression where the dependent variable is 0 if the respondent is a stayer or a mover, and 1 if the respondent is a leaver. A positive coefficient thus indicates a positive relation between the variable and the likelihood that the worker leaves the public sector.

We find that employees who quit their public sector job out of dissatisfaction with rewards, financial prospects, or management are more likely to move to a job in the private sector. Similar, but somewhat less strong effects are found for physical working conditions and future job duties. This resembles the reasons given by UK workers for their exit from the public sector (Audit Commission, 2002). Employees with children are less likely to leave the public sector, suggesting that it is easier to combine the care for children with working in the public sector than with working in the private sector. Likewise, Table 5 suggests that the public sector offers better conditions regarding the opportunities for education and training than the private sector. These findings are an indication of the relative strengths and weaknesses of public sector jobs. Yet, a similar analysis among private sector workers is needed for a more conclusive comparison between public and private sector jobs.

The relatively high discontent with management among workers who leave the public sector may be related to Dixit's (2002) observation that public agencies often face multiple principals. When the management of a public agency is unable to translate the diverse interests and pressures of the principals into a clear organisational goal and consistent objectives, workers may lose confidence in their management's capacities. Private firms are less prone to pursue conflicting goals, as the ultimate objective of a private firm is to generate shareholder value. 


\subsection{The wage effects of a change in industry}

Section 4 analysed the effect of workers' reasons for quitting on their wage development, without examining directly the effect of a change in industry. By exploring differences in wage growth between stayers, movers and leavers, we can compare the wage growth of intra-industry job movers (stayers) to the wage growth of interindustry job movers (movers and leavers). Table 6 presents the differences in wage growth between intraand interindustry job mover, both with and without controlling for workers' reasons for quitting. ${ }^{12}$ The estimation without the reason-to-quit variables indicates that leavers obtain a significantly larger wage increase than stayers. Lima (2004) reports a wage premium for a change in industry of similar magnitude in a large sample of Portuguese workers. However, the second column of Table 6 makes clear that the differences in wage growth between stayers, movers, and leavers are fully explained by differences in the reasons for quitting the initial job. Hence, we conclude that neglecting workers' reasons to quit may yield incorrect estimates of the effect of a change in industry on wage growth.

Data limitations prevent differentiating between workers entering, leaving, or staying in specific industries. Studies using matched employeremployee data have shown that unobserved worker heterogeneity explains most of the interindustry wage differentials (Abowd et al., 1999, Goux and Maurin, 1999). Relatedly, McLaughlin and Bils (2001), who find that workers leaving declining industries and workers entering growing industries tend to have higher wage growth than their new colleagues who did not change industry, conjecture that "the wage changes of interindustry movers could be [explained] by an extension to compensating wage differentials for industry attributes" (p. 131). Although on a more aggregate level, the results in Table 6 confirm that differences in wage growth between intra- and interindustry job movers may be explained by heterogeneous preferences for industry-specific components of job characteristics.

\footnotetext{
${ }^{12}$ The difference with the estimations in Table 3 is that the dummies for the new industry of employment have been replaced by dummies for movers and leavers, with stayers as base category.
} 


\section{Conclusions}

Using survey data among public sector workers in the Netherlands, this paper has shown that job movers' experience in their initial job affects their decision to stay in or leave their industry of employment. When pay, work pressure, working conditions, job duties, or management are important in the decision to quit, workers are more likely to move out of their industry. By contrast, a quit because of the atmosphere at work, commuting time, the opportunities for training, or working hours makes a change in industry less likely. This suggests that workers use their experience in the initial job to update their expectations on other jobs in the industry, as the first set of job aspects is more likely to be related among jobs within an industry than the latter. Moreover, we show that different motives for quitting lead to differences in wage growth, as the apparent wage premium of interindustry job movers relative to intra-industry job movers vanishes once workers' reasons to quit are controlled for. Lastly, we find that many workers who quit out of dissatisfaction with pay or management leave the public sector altogether. Hence, improvement of these job aspects should receive priority if employee turnover in the public sector is to be reduced.

A similar, but economy-wide survey of job movers would improve the analysis of the effects of workers' reasons for quitting. With the addition of job movers within the private sector, an analysis of the relatively attractive and repulsive aspects of public sector jobs would be feasible. Moreover, a larger sample size would enable us to assess the main reasons for entering and leaving specific industries. As called for by McLaughlin and Bils (2001), this may facilitate the estimation of industry attributes and their effect on workers' wages.

\section{Acknowledgements}

I am grateful to Robert Dur for guidance and encouragement. I would like to thank Andrew Clark, Silvia Dominguez Martinez, Chaim Fershtman, Richard Paap, Otto Swank, and attendents of seminars in Rotterdam and Amsterdam for useful comments and suggestions. 


\section{References}

[1] Abowd, John M., Kramarz, Francis, and Margolis, David N. (1999) High Wage Workers and High Wage Firms, Econometrica, Vol. 67 (2), pp. 251-333.

[2] Akerlof, George A., Rose, Andrew K., and Yellen, Janet L. (1988) Job Switching and Job Satisfaction in the Labor Market, Brookings Papers on Economic Activity, Vol. 2, pp. 495-582.

[3] Altonji, Joseph G. and Paxson, Christina H., 1992, Labor Supply, Hours Constraints, and Job Mobility, Journal of Human Resources, Vol. 27 (2), pp. 256-278.

[4] Audit Commission (2002) Recruitment and Retention: A Public Service Workforce for the Twenty-First Century (url: http://www.auditcommission.gov.uk/reports).

[5] Bartel, Ann P. (1982) Wages, Nonwage Job Characteristics, and Labor Mobility, Industrial and Labor Relations Review, Vol. 35 (4), pp. 578-589.

[6] Blau, Francine D. and Ferber, Marianne A. (1986) The Economics of Women, Men, and Work, Prentice-Hall, Englewood Cliffs.

[7] Borjas, George J., (2003) The Wage Structure and the Sorting of Workers into the Public Sector, in For the People; Can We Fix Public Service? (Eds.) Donahue, John D. and Nye, Joseph S. Jr., Brookings Institution Press, Washington, D.C., pp. 29-54.

[8] Brown, Sarah and Sessions, John G., (2002) Supervisor Heterogeneity: An Analysis of UK Microdata, Scottish Journal of Political Economy, Vol. 49 (4), pp. 407-417.

[9] Brunello, Giorgio, (1995) The Relationship between Supervision and Pay: Evidence from the British New Earnings Survey, Oxford Bulletin of Economics and Statistics, Vol. 57 (3), pp. 309-321 
[10] Campbell, David, (2001) Estimating the Wage effects of Job Mobility in Britain, University of Kent, Department of Economics Discussion Paper 01/17.

[11] Clark, Andrew E., (2001) What Really Matters in a Job? Hedonic Measurement Using Quit Data, Labour Economics, Vol. 8, pp. 223242 .

[12] Clark, Andrew E., Georgellis, Yannis, and Sanfey, Peter, (1998) Job Satisfaction, Wage Changes, and Quits: Evidence from Germany, Research in Labor Economics, Vol. 17, pp. 95-121.

[13] Connolly, Helen and Gottschalk, Peter, (2000) Returns to Tenure and Experience Revisited-Do Less Educated Workers Gain Less from Work Experience? Boston College Working Paper Series No. 473.

[14] Dixit, Avinash, (2002) Incentives and Organizations in the Public Sector: An Interpretative Review, Journal of Human Resources, Vol. 37 (4), pp. 696-727.

[15] Dur, Robert and Glazer, Amihai, (2004) The Desire for Impact, Tinbergen Institute Discussion Paper no. 04-115/1.

[16] Freeman, R.B., (1978) Job Satisfaction as an Economic Variable, American Economic Review, Vol. 68 (2), pp. 135-141.

[17] Frey, Bruno S. and Kucher, Marcel, (1999) Managerial Power and Compensation, Institute for Empirical Research in Economics Working Paper No. 28, University of Zurich.

[18] Goux, Dominique and Maurin, Eric, (1999) Persistence of Interindustry Wage Differentials: A Reexamination Using Matched WorkerFirm Panel Data, Journal of Labor Economics, Vol. 17 (3), pp. 492533.

[19] Johnson, William R., (1978) A Theory of Job Shopping, Quarterly Journal of Economics, Vol. 92 (2), pp. 261-277.

[20] Jovanovic, Boyan, (1979) Job Matching and the Theory of Turnover, Journal of Political Economy, Vol. 87 (5), pp. 972-990. 
[21] Keith, Kristen and McWilliams, Abagail, (1997) Job Mobility and Gender-Based Wage Growth Differentials, Economic Inquiry, Vol 35 (2), pp. 320-333.

[22] Kletzer, Lori G., (1998) Job Displacement, Journal of Economic Perspectives, Vol. 12 (1), pp. 115-136.

[23] Kristensen, Nicolai and Westergard-Nielsen, Niels, (2004) Does Low Job Satisfaction Lead to Job Mobility? IZA Discussion Paper No. 1026.

[24] Krueger, Alan B., (1991) Ownership, Agency, and Wages: An Examination of Franchising in the Fast Food Industry, Quarterly Journal of Economics, Vol. 106 (1), pp. 75-101.

[25] Kruse, Douglas, (1992) Supervision, Working Conditions, and the Employer Size-Wage effect, Industrial Relations, Vol. 31 (2), pp. 229249.

[26] Kuhn, Peter., (2002) Losing Work, Moving On: Worker Displacement in International Perspective, W. E. Upjohn Institute for Employment Research.

[27] Leonard, Jonathan S., (1987) Carrots and Sticks: Pay, Supervision, and Turnover, Journal of Labor Economics, Vol. 5 (4), pp. S136-S152.

[28] Light, Audrey and McGarry, Kathleen, (1998) Job Change Patterns and the Wages of Young Men, Review of Economics and Statistics, Vol. 80 (2), pp. 276-286.

[29] Lima, Francisco, (2004) How Much Mobility? Careers, Promotions, and Wages, CEG-IST Research Paper No. 3/2004.

[30] Loprest, Pamela J., (1992) Gender Differences in Wage Growth and Job Mobility, American Economic Review, Vol. 82 (2), pp. 526-532.

[31] Mathios, Alan D., (1989) Education, Variation in Earnings, and Nonmonetary Compensation, Journal of Human Resources, Vol. 24 (3), pp. 456-468. 
[32] McLaughlin, Kenneth J., (1991) A Theory of Quits and Layoffs with Efficient Turnover, Journal of Political Economy, Vol. 99 (1), pp. $1-29$.

[33] McLaughlin, Kenneth J. and Bils, Mark, (2001) Interindustry Mobility and the Cyclical Upgrading of Labor, Journal of Labor Economics, Vol. 19 (1), pp. 94-135.

[34] Neal, Derek, (1999) The Complexity of Job Mobility among Young Men, Journal of Labor Economics, Vol. 17 (2), pp. 237-261.

[35] OECD, (2001) Public Sector - An Employer of Choice? Report on the Competitive Employer Project, OECD Public Management Service.

[36] Polachek, Solomon W. and Kim, Moon-Kak, (1994) Panel Estimates of the Gender Earnings Gap, Journal of Econometrics, Vol. 61 (1), pp. 23-42.

[37] Rebitzer, James B., (1995), Is There a Trade-off between Supervision and Wages? An Empirical Test of Efficiency Wage Theory, Journal of Economic Behavior and Organization, Vol. 28 (1), pp. 107-129.

[38] Smith, Michael, Masi, Anthony, and Lemay, Paula, (1997) The Determinants of Blue Collar Wage Rates: An Analysis of a Dataset Incorporating Observed Job Characteristics, Labour, Vol 11 (1), pp. 113-140.

[39] Topel, Robert H. and Ward, Micheal P., (1992) Job Mobility and the Careers of Young Men, Quarterly Journal of Economics, Vol. 107 (2), pp. 439-479.

[40] Villanueva, Ernesto, (2004) Compensating Wage Differentials and Voluntary Job Changes: Evidence from West Germany, Mimeo, University of Pompeu Fabra.

[41] Viscusi, W.K., (1979) Job Hazards and Worker Quit Rates: An Analysis of Adaptive Worker Behavior, International Economic Review, Vol. 20 (1), pp. 29-58. 
[42] Weiss, Andrew, (1984) Determinants of Quit Behavior, Journal of Labor Economics, Vol. 2 (3), pp. 371-387.

[43] Weiss, Yoram and Gronau, Reuben, (1981) Expected Interruptions in Labour Force Participation and Sex-related Differences in Earnings Growth, Review of Economic Studies, Vol. 48 (4), pp. 607-619. 
Table 1: Means of the reason-to-quit variables

\begin{tabular}{lccccc} 
Reasons to quit & All & Stayers & Movers & Leavers & Entrants \\
\hline Threat of restructuring & 0.22 & 0.17 & 0.18 & 0.14 & 0.35 \\
Threat of losing job & 0.20 & 0.18 & 0.19 & 0.13 & 0.26 \\
Duration of contract & 0.32 & 0.37 & 0.37 & 0.24 & 0.24 \\
Rewards & 0.62 & 0.52 & 0.63 & 0.84 & 0.65 \\
Financial prospects & 0.79 & 0.66 & 0.79 & 1.06 & 0.85 \\
Work pressure & 0.61 & 0.64 & 0.60 & 0.47 & 0.64 \\
Facilities at work & 0.26 & 0.25 & 0.24 & 0.25 & 0.28 \\
Physical working conditions & 0.32 & 0.26 & 0.29 & 0.27 & 0.44 \\
Job duties & 1.17 & 0.90 & 1.38 & 1.16 & 1.35 \\
Future job duties & 1.16 & 1.02 & 1.36 & 1.38 & 1.11 \\
Education / training & 0.57 & 0.45 & 0.54 & 0.43 & 0.79 \\
Atmosphere & 1.06 & 1.13 & 0.96 & 0.98 & 1.07 \\
Contractual hours & 0.32 & 0.28 & 0.23 & 0.19 & 0.49 \\
Combination work and family life & 0.69 & 0.74 & 0.61 & 0.52 & 0.75 \\
Commuting time & 0.71 & 0.98 & 0.59 & 0.34 & 0.63 \\
Personnel management & 0.87 & 0.84 & 0.86 & 1.20 & 0.78 \\
Management of the organisation & 0.91 & 0.81 & 0.98 & 1.26 & 0.84 \\
Style of leadership & 1.00 & 1.01 & 1.03 & 1.28 & 0.86 \\
Autonomy / responsibility & 0.86 & 0.84 & 0.91 & 0.92 & 0.88 \\
Observations & 6115 & 2197 & 1396 & 689 & 1833 \\
\hline
\end{tabular}

Data source: BZK, Mobiliteitsonderzoek 2002. 
Table 2: Summary statistics

\begin{tabular}{|c|c|c|c|c|}
\hline Variables & Stayers & Movers & Leavers & Entrants \\
\hline \multirow[t]{2}{*}{ Female } & 0.532 & 0.542 & 0.379 & 0.462 \\
\hline & $(0.499)$ & $(0.498)$ & $(0.486)$ & $(0.499)$ \\
\hline \multirow[t]{2}{*}{ Minority } & 0.029 & 0.038 & 0.042 & 0.054 \\
\hline & $(0.167)$ & $(0.191)$ & $(0.200)$ & $(0.226)$ \\
\hline \multirow[t]{2}{*}{ Married / cohabitating } & 0.806 & 0.766 & 0.777 & 0.680 \\
\hline & $(0.395)$ & $(0.424)$ & $(0.416)$ & $(0.467)$ \\
\hline \multirow[t]{2}{*}{ Kids at home } & 0.535 & 0.473 & 0.435 & 0.368 \\
\hline & $(0.499)$ & $(0.499)$ & $(0.496)$ & $(0.483)$ \\
\hline \multirow[t]{2}{*}{ Low education } & 0.035 & 0.074 & 0.073 & 0.136 \\
\hline & $(0.185)$ & $(0.261)$ & $(0.261)$ & $(0.343)$ \\
\hline \multirow[t]{2}{*}{ Medium education } & 0.140 & 0.209 & 0.256 & 0.337 \\
\hline & $(0.347)$ & $(0.407)$ & $(0.437)$ & $(0.473)$ \\
\hline \multirow[t]{2}{*}{ Higher vocational education } & 0.604 & 0.392 & 0.379 & 0.304 \\
\hline & $(0.489)$ & $(0.488)$ & $(0.485)$ & $(0.460)$ \\
\hline \multirow[t]{2}{*}{ University } & 0.221 & 0.325 & 0.292 & 0.223 \\
\hline & $(0.415)$ & $(0.469)$ & $(0.455)$ & $(0.416)$ \\
\hline \multirow[t]{2}{*}{ Tenure (in years) } & 7.370 & 6.870 & 7.060 & 4.690 \\
\hline & $(7.427)$ & $(6.615)$ & $(6.670)$ & $(5.463)$ \\
\hline \multirow[t]{2}{*}{ Experience (in years) } & 13.635 & 11.684 & 11.490 & 10.051 \\
\hline & $(9.326)$ & $(8.701)$ & $(8.109)$ & $(8.276)$ \\
\hline \multirow[t]{2}{*}{ Hours worked in old job } & 33.024 & 32.586 & 35.379 & 32.819 \\
\hline & $(7.941)$ & $(7.900)$ & $(5.688)$ & $(8.859)$ \\
\hline \multirow[t]{2}{*}{ Hours worked in new job } & 33.186 & 32.913 & 35.473 & 34.079 \\
\hline & $(7.764)$ & $(7.421)$ & $(5.293)$ & $(7.034)$ \\
\hline \multirow[t]{2}{*}{ Hourly wage old job $(€)$} & 15.611 & 14.855 & 15.591 & 12.643 \\
\hline & $(5.581)$ & $(5.884)$ & $(6.109)$ & $(5.967)$ \\
\hline \multirow[t]{2}{*}{ Hourly wage new job $(€)$} & 16.978 & 16.406 & 17.424 & 13.761 \\
\hline & $(6.346)$ & $(6.696)$ & $(7.250)$ & $(6.066)$ \\
\hline \multirow[t]{2}{*}{$\Delta \log$ hourly wage } & 0.079 & 0.096 & 0.105 & 0.098 \\
\hline & $(0.180)$ & $(0.241)$ & $(0.219)$ & $(0.257)$ \\
\hline Observations & 2197 & 1396 & 689 & 1833 \\
\hline
\end{tabular}

Data source: BZK, Mobiliteitsonderzoek 2002.

Standard deviations in parentheses. 
Table 3: OLS estimation of the effects of the reason-to-quit variables on wage growth

Reasons to quit excluded Reasons to quit included

\begin{tabular}{|c|c|c|c|c|}
\hline Variable & Coefficient & $\mathbf{S E}$ & Coefficient & SE \\
\hline Constant & $0.112^{* * *}$ & $(0.019)$ & $0.054^{* *}$ & $(0.021)$ \\
\hline Female & 0.000 & $(0.006)$ & $0.011^{*}$ & $(0.006)$ \\
\hline Minority & 0.012 & $(0.014)$ & 0.002 & $(0.014)$ \\
\hline Married & $-0.022^{* * *}$ & $(0.007)$ & $-0.017^{* *}$ & $(0.007)$ \\
\hline Kids at home & 0.006 & $(0.006)$ & 0.008 & $(0.007)$ \\
\hline Medium education & $0.021^{*}$ & $(0.012)$ & $0.021^{*}$ & $(0.012)$ \\
\hline Higher voc. education & $0.044^{* * *}$ & $(0.012)$ & $0.048^{* * *}$ & $(0.012)$ \\
\hline University & $0.040^{* * *}$ & $(0.013)$ & $0.046^{* * *}$ & $(0.013)$ \\
\hline Threat of restructuring & & & $-0.009 * *$ & $(0.004)$ \\
\hline Threat of losing job & & & $-0.009^{* *}$ & $(0.004)$ \\
\hline Duration of contract & & & 0.004 & $(0.003)$ \\
\hline Rewards & & & $0.027^{* * *}$ & $(0.003)$ \\
\hline Financial prospects & & & $0.014^{* * *}$ & $(0.003)$ \\
\hline Work pressure & & & $-0.012^{* * *}$ & $(0.003)$ \\
\hline Facilities at work & & & 0.001 & $(0.005)$ \\
\hline Working conditions & & & -0.001 & $(0.004)$ \\
\hline Job duties & & & 0.003 & $(0.002)$ \\
\hline Future job duties & & & 0.001 & $(0.002)$ \\
\hline Training & & & -0.002 & $(0.003)$ \\
\hline Atmosphere & & & 0.001 & $(0.002)$ \\
\hline Contractual hours & & & $0.008^{* *}$ & $(0.004)$ \\
\hline Work vs private life & & & $-0.007 * * *$ & $(0.003)$ \\
\hline Commuting time & & & -0.003 & $(0.002)$ \\
\hline Pers. management & & & 0.002 & $(0.003)$ \\
\hline Management org. & & & -0.001 & $(0.003)$ \\
\hline Style of leadership & & & 0.002 & $(0.003)$ \\
\hline Autonomy/responsibility & & & $0.010^{* * *}$ & $(0.002)$ \\
\hline $\mathrm{R}^{2}$ & 0.076 & & 0.118 & \\
\hline Observations & 6115 & & 6115 & \\
\hline
\end{tabular}

Data source: BZK, Mobiliteitsonderzoek 2002.

* significant at the 0.10 level. ** significant at the 0.05 level. *** significant at the 0.01 level. Also included, but not reported, were the change in the number of working hours, tenure, tenure-squared, experience, experience-squared and dummies for the former and new sector of employment. 
Table 4: Reasons to stay in or leave the industry

\begin{tabular}{|c|c|c|}
\hline \multicolumn{3}{|c|}{ Dependent variable: $0=$ stayer, $1=$ mover or leaver } \\
\hline Variable & Coefficient & $\mathrm{SE}$ \\
\hline Constant & $2.702^{* * *}$ & $(0.434)$ \\
\hline Female & -0.071 & $(0.083)$ \\
\hline Minority & 0.284 & $(0.197)$ \\
\hline Married & 0.015 & $(0.094)$ \\
\hline Kids at home & $-0.143^{*}$ & $(0.085)$ \\
\hline Medium education & -0.215 & $(0.189)$ \\
\hline Higher voc. education & $-0.533^{* * *}$ & $(0.192)$ \\
\hline University & -0.190 & $(0.208)$ \\
\hline Log hourly wage old job & $-0.353^{* * *}$ & $(0.130)$ \\
\hline Threat of restructuring & -0.003 & $(0.056)$ \\
\hline Threat of losing job & 0.048 & $(0.056)$ \\
\hline Duration of contract & $-0.076^{*}$ & $(0.041)$ \\
\hline Rewards & $0.096^{* * *}$ & $(0.036)$ \\
\hline Financial prospects & $0.095^{* * *}$ & $(0.034)$ \\
\hline Work pressure & $0.099^{* * *}$ & $(0.034)$ \\
\hline Facilities at work & -0.020 & $(0.069)$ \\
\hline Working conditions & $0.138^{* *}$ & $(0.054)$ \\
\hline Job duties & $0.141^{* * *}$ & $(0.028)$ \\
\hline Future job duties & $0.115^{* * *}$ & $(0.030)$ \\
\hline Training & $-0.171^{* * *}$ & $(0.044)$ \\
\hline Atmosphere & $-0.079 * * *$ & $(0.029)$ \\
\hline Contractual hours & $-0.119^{* *}$ & $(0.058)$ \\
\hline Work vs private life & -0.026 & $(0.036)$ \\
\hline Commuting time & $-0.193^{* * *}$ & $(0.034)$ \\
\hline Pers. management & 0.040 & $(0.035)$ \\
\hline Management org. & $0.212^{* * *}$ & $(0.035)$ \\
\hline Style of leadership & $0.081^{* *}$ & $(0.032)$ \\
\hline Autonomy/responsibility & -0.021 & $(0.031)$ \\
\hline Nagelkerke's $\mathrm{R}^{2}$ & 0.315 & \\
\hline Observations & 4282 & \\
\hline
\end{tabular}

Data source: BZK, Mobiliteitsonderzoek 2002.

* significant at the 0.10 level. ${ }^{* *}$ significant at the 0.05 level. ${ }^{* * *}$ significant at the 0.01 level. Also included, but not reported, were the number of working hours, tenure, tenure-squared, experience, experience-squared, and dummies for the former sector of employment. 
Table 5: Reasons to stay in or leave the public sector

\begin{tabular}{|c|c|c|}
\hline Variable & Coefficient & SE \\
\hline Constant & $-2.217^{* * *}$ & $(0.557)$ \\
\hline Female & -0.229 & $(0.105)$ \\
\hline Minority & 0.197 & $(0.231)$ \\
\hline Married & 0.078 & $(0.118)$ \\
\hline Kids at home & $-0.280^{* * *}$ & $(0.106)$ \\
\hline Medium education & 0.113 & $(0.206)$ \\
\hline Higher voc. education & $-0.392^{*}$ & $(0.220)$ \\
\hline University & -0.214 & $(0.240)$ \\
\hline Log hourly wage old job & 0.171 & $(0.167)$ \\
\hline Threat of restructuring & -0.024 & $(0.075)$ \\
\hline Threat of losing job & -0.045 & $(0.079)$ \\
\hline Duration of contract & $-0.117^{* *}$ & $(0.059)$ \\
\hline Rewards & $0.153^{* * *}$ & $(0.042)$ \\
\hline Financial prospects & $0.131^{* * *}$ & $(0.041)$ \\
\hline Work pressure & -0.015 & $(0.048)$ \\
\hline Facilities at work & -0.015 & $(0.089)$ \\
\hline Working conditions & $0.132^{*}$ & $(0.071)$ \\
\hline Job duties & 0.008 & $(0.036)$ \\
\hline Future job duties & $0.092^{* *}$ & $(0.038)$ \\
\hline Training & $-0.178^{* * *}$ & $(0.065)$ \\
\hline Atmosphere & -0.029 & $(0.038)$ \\
\hline Contractual hours & -0.074 & $(0.084)$ \\
\hline Work vs private life & -0.063 & $(0.050)$ \\
\hline Commuting time & $-0.380^{* * *}$ & $(0.057)$ \\
\hline Pers. management & $0.121^{* * *}$ & $(0.042)$ \\
\hline Management org. & $0.154^{* * *}$ & $(0.041)$ \\
\hline Style of leadership & $0.108^{* * *}$ & $(0.039)$ \\
\hline Autonomy/responsibility & 0.013 & $(0.039)$ \\
\hline Nagelkerke's $\mathrm{R}^{2}$ & 0.180 & \\
\hline Observations & 4282 & \\
\hline
\end{tabular}

Data source: BZK, Mobiliteitsonderzoek 2002.

* significant at the 0.10 level. ** significant at the 0.05 level. *** significant at the 0.01 level. Also included, but not reported, were the number of working hours, tenure, tenure-squared, experience, experience-squared, and dummies for the former sector of employment. 
Table 6: Reasons to quit and the wage growth of intra- and interindustry job movers

\section{Reasons to quit excluded Reasons to quit included}

\begin{tabular}{lrrrr} 
Variable & Coefficient & SE & Coefficient & SE \\
\hline Movers & 0.007 & $(0.008)$ & 0.002 & $(0.007)$ \\
Leavers & $0.016^{*}$ & $(0.009)$ & 0.001 & $(0.009)$ \\
Reasons to quit & NO & & YES & \\
$\mathrm{R}^{2}$ & 0.088 & 0.125 & \\
Observations & 4282 & 4282 & \\
\hline
\end{tabular}

Data source: BZK, Mobiliteitsonderzoek 2002.

* significant at the 0.10 level. ${ }^{* *}$ significant at the 0.05 level. ${ }^{* * *}$ significant at the 0.01 level. Except for the dummies for the new sector of employment, all variables included in the specifications of Table 3 are also included here. 